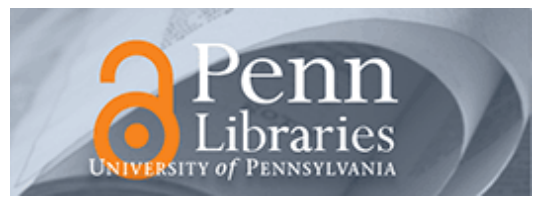

University of Pennsylvania

ScholarlyCommons

\title{
Early Childhood Experiences and Kindergarten Success: A Population-Based Study of a Large Urban Setting
}

John Fantuzzo

University of Pennsylvania, JOHNF@GSE.UPENN.EDU

Heather L. Rouse

University of Pennsylvania, rouseh@gse.upenn.edu

Paul McDermott

University of Pennsylvania

Stephen Childs

Andrea Weiss

Follow this and additional works at: https://repository.upenn.edu/gse_pubs

Part of the Early Childhood Education Commons

\section{Recommended Citation}

Fantuzzo, J., Rouse, H. L., McDermott, P., Childs, S., \& Weiss, A. (2005). Early Childhood Experiences and Kindergarten Success: A Population-Based Study of a Large Urban Setting. 34 (4), 571-588. Retrieved from https://repository.upenn.edu/gse_pubs/436 


\title{
Early Childhood Experiences and Kindergarten Success: A Population-Based Study of a Large Urban Setting
}

\author{
Abstract \\ This study examined the unique protective influence of center-based early care and education \\ experiences on kindergarten outcomes for children entering public school kindergarten. The 3,969 \\ participants were geographically and demographically representative of an entire kindergarten cohort in a \\ large urban school district. Child age, gender, ethnicity, family poverty, low maternal education, and \\ neighborhood were found to be risks for academic and behavioral adjustment upon kindergarten entry. \\ Controlling for these risks, formal, center-based experiences were related significantly to higher levels of \\ Language Arts, Mathematics, Social Knowledge, Motor Skills, and Work Habits performance assessments \\ and attendance in kindergarten. Initial advantages associated with center-based early care and education \\ were sustained across the kindergarten year.
}

\section{Keywords}

childhood, kindergarten, urban, population

Disciplines

Early Childhood Education | Education 


\title{
Early Childhood Experiences and Kindergarten Success: A Population-Based Study of a Large Urban Setting
}

\author{
John W. Fantuzzo, Heather L. Rouse, Paul A. McDermott, \\ and Yumiko Sekino \\ University of Pennsylvania
}

\author{
Stephanie Childs and Andrea Weiss \\ School District of Philadelphia
}

\begin{abstract}
This study examined the unique protective influence of center-based early care and education experiences on kindergarten outcomes for children entering public school kindergarten. The 3,969 participants were geographically and demographically representative of an entire kindergarten cohort in a large urban school district. Child age, gender, ethnicity, family poverty, low maternal education, and neighborhood were found to be risks for academic and behavioral adjustment upon kindergarten entry. Controlling for these risks, formal, center-based experiences were related significantly to higher levels of Language Arts, Mathematics, Social Knowledge, Motor Skills, and Work Habits performance assessments and attendance in kindergarten. Initial advantages associated with center-based early care and education were sustained across the kindergarten year.
\end{abstract}

Three recent National Research Council reports document the impact of early experiences on school achievement-Eager to Learn (2001), From Neurons to Neighborhoods (2000), and Preventing Reading Difficulties in Young Children (Snow, Burns, \& Griffin, 1998). Each report highlights two major realities drawn from early childhood research: (a) the adverse effects of multiple early risk factors on later school functioning, and (b) the capacity of early intervention to increase favorable outcomes for vulnerable children living in high risk environments. Of particular concern are multiple risks faced by children living in poverty (Egeland, Carlson, \& Sroufe, 1993).

Currently, $40 \%$ of children under age 6 live in households with incomes below 200\% of poverty (National Center for Children in Poverty, 2002). These children are more likely than their economically advantaged peers to

\footnotetext{
Author Note. This research project was supported in part by grants from the William Penn Foundation and the National Institute of Health and Human Development. Special thanks go to our collaborators at Office of Early Childhood Education in the School District of Philadelphia. This includes Donna Piekarski, Administrator; Jennifer Plumer Davis, Director of the Prekindergarten Head Start Program; and Ernestine Redd, Director of Comprehensive Early Learning Center.
}

Correspondence concerning this article should be addressed to John W. Fantuzzo, The Penn Graduate School of Education, University of Pennsylvania, 3700 Walnut Street, Philadelphia, PA 19104-6216: Email: johnf@gse.upenn.edu

Copyright 2005 by the National Association of School Psychologists, ISSN 0279-6015 
demonstrate early and persistent school difficulties, including poor academic performance, grade retention, and emotional/behavioral problems (Axinn, Duncan, \& Thornton, 1997; Duncan, Brooks-Gunn, \& Klebanov, 1994). Furthermore, poverty concentrated in large urban centers is associated with the existence of multiple health and social environmental risk factors that have a negative impact on educational and social/emotional outcomes (Coulton \& Pandey, 1992; U.S. Department of Education, 1996). Research has documented significant relationships between child outcomes and child and family health factors such as low birth weight, exposure to lead, and maternal mental health (Axinn, Duncan, \& Thornton, 1997). Similarly, empirical evidence highlights relations between family social risks, such as poverty, maternal education, family literacy, and family social support, and children's academic achievement (Christian, Morrison, \& Bryant, 1998; Duncan, Brooks-Gunn, \& Klebanov, 1994). Research findings confirm that many of these factors have a significant negative effect on child development that persists throughout elementary and secondary school (Axinn, Duncan, \& Thornton, 1997; Klebanov, BrooksGunn, \& McCormick, 1994).

A recent population-based, school readiness evaluation identified the impact of multiple environmental and social risk factors on the academic and social development of an entire cohort of children entering public elementary school in a large urban center (Weiss \& Fantuzzo, 2001). Researchers found that nearly $80 \%$ of children entering first grade had experienced at least one major risk factor. Many of these risk factors were evident from birth, such as exposure to lead, low birth weight, birth to a teen parent, poor prenatal care, and out of home placements. Findings indicated that controlling for poverty and age, both environmental and social factors significantly increased children's risk for academic and behavioral problems as well as high absenteeism and grade retention.

Independent studies have found that physical and social dimensions of neighborhood risk threaten child development. Families living in poverty often reside in neighbor- hoods with deleterious housing that creates health and safety hazards for children (e.g., exposed lead paint, abandoned properties; Coulton, Korbin, \& Su, 1996; Wilson, 1987). A myriad of social problems are also associated with poverty. Density of social problems in a neighborhood, such as community violence, high rates of teen birth, delinquency, and truancy, have been found to adversely affect various domains of child functioning (Coulton, Korbin, Su, \& Chow, 1995; Farver, Natera, \& Frocsh, 1999). In accordance with a developmental-ecological model, inclusion of these dimensions will enhance our understanding of neighborhood risk and child development (Leventhal \& Brooks-Gunn, 2003).

In addition to the identification of individual child and neighborhood risk factors, population-based studies allow researchers to examine heterogeneous outcomes of vulnerable children to identify strengths. Not all children exposed to risk factors manifest poor outcomes. Proponents for the study of resilience explore the transactional processes between individual characteristics and family or environmental factors that could account for these heterogeneous outcomes (Luthar, Cicchetti, \& Becker, 2000). This perspective defines resilience as a multidimensional construct composed of individual and contextual features that help explain positive adaptation for children living in adverse circumstances.

Participation in quality early learning experiences has been identified as one such factor that promotes resilient outcomes for vulnerable children (National Research Council, 2001). Particularly for children from lowincome families, participation in center-based preschool programs is associated with shortand long-term increases in achievement and school success (Barnett, 1995). Evaluations of specific programs designed to enhance school readiness for young children have demonstrated significant gains in cognitive and social/behavioral outcomes for participants (e.g., Cost, Quality and Outcomes [Peisner-Feinberg, et al., 2001], the High Scope/Perry Preschool Project [Schweinhart \& Weikart, 1997], and Abcedarian Project [Campbell, Pungelo, Miller-Johnson, Burchinal, \& Ramey, 2001]). 
Research further documents that children who experience greater risk early in life (such as living in poverty) evidence greater benefit from participation in early learning experiences (Hubbs-Tait et al., 2002).

A prospective study sponsored by the National Institute of Child Health and Human Development recently examined the impact of child care on early development across 10 nationally representative sites (NICHD Early Child Care Research Network, 1994). Findings to date show that overall experience in center care was associated with better social-emotional and cognitive-linguistic outcomes (NICHD Early Child Care Research Network, 2000,2002 ). With respect to the study of children at high risk for early school difficulties, this study is qualified by its initial exclusion criteria. Populations of children who were born to teen mothers, whose family did not speak English, who were placed for adoption, or who lived in a neighborhood "deemed by police too unsafe for visitation" were excluded from study participation (NICHD Early Child Care Research Network, 2001a). These groups of children evidence significant risk factors that have known relationships with later school success (Berry, 1992; Brooks-Gunn \& Chase-Lansdale, 1995), and their exclusion precludes generality of the study findings. Population-based research is needed to determine if similar protective effects are found for groups of children evidencing the full range of risk factors.

The purpose of the present research was to gain a better understanding of the protective benefits of center-based early care and education for a representative sample of kindergarten children from a large urban school district. The relationships between centerbased experiences and kindergarten academic achievement and behavioral adjustment were examined upon kindergarten entry and across the academic year. Two major research questions were addressed to determine the unique benefits of center-based experiences. First, what is the effect of major neighborhood (high densities of physical and social risk factors) and family context variables on academic and behavioral difficulties at kindergarten entry? Second, what is the unique contribution of cen- ter-based early childhood experiences to readiness for kindergarten and success in kindergarten controlling for significant risk factors? This question involved an assessment of children's performance at three points in time during the kindergarten year: in the fall, at the midpoint, and at the end of the academic year. We hypothesized that the density of neighborhood distress, family poverty, and lower level of maternal education would constitute a significant risk for poor skill levels at kindergarten entry. Additionally we hypothesized that center-based early childhood experiences would be associated with enhanced skill levels at entry and throughout kindergarten controlling for neighborhood and family risks.

\section{Methods}

\section{Participants}

A representative sample of 3,969 kindergarten children participated in this study. Children were equally distributed between males $(51 \%)$ and females (49\%), with an average age of 66 months at kindergarten entry. Sixty-four percent of the children were African American, $17 \%$ Caucasian, $15 \%$ Hispanic, $4 \%$ Asian, and $.1 \%$ Native American'. These children comprised a representative sample of children born in the urban center enrolled in public school kindergarten. They were drawn from kindergarten classrooms across 172 elementary schools. All kindergarten classrooms in the school district operate for a full day. The participating classrooms were selected to be representative of the nine geographic school district regions and the demographics of the entire cohort of 15,343 kindergarten students. The demographic breakdown of the entire cohort was $51 \%$ male, $62 \%$ African American, $18 \%$ Caucasian, $16 \%$ Hispanic, 5\% Asian, and .1\% Native American. The overall participation rate was $72 \%$. A linkage between the school district and vital statistics database for the city indicated that $78 \%$ of the children in the cohort were born in the city.

\section{Measures}

Early care and education experiences. The Early Care and Education Interview (ECEI) is a structured parent-teacher in- 
terview designed to collect information about children's pre-kindergarten early care and learning experiences (birth to 5 years of age) (Fantuzzo \& Cohen, 2003). The interview format consists of a series of questions for children entering kindergarten for the first time. There are nine specific types of early care and education experiences derived from the National Association for the Education of Young Children's accreditation standards and the National Institute of Child Health and Human Development Study of Early Child Care (NAEYC, 1998; NICHD Early Child Care Research Network, 2001a). These nine types of experiences were categorized into three main groups: CenterBased care, Informal care, and No Extra care. Center-based care is defined as care provided in a location such as a business or religious program for more than 10 children, and is often referred to as "center care" (NICHD Early Child Care Research Network, 2001a). Center-based care experiences include nationally funded programs such as Head Start (fully subsidized multigenerational program for low-income children aged 3-5 and their parents), locally funded programs such as the school district day care program (partially subsidized program serving 3to 5-year-old, low-income children of working parents who do not meet guidelines for Head Start) and parent cooperative nursery (partially subsidized program serving children from birth to age 5 where parents are required to participate in everyday program operations), and privately run center-based care. Informal care includes three different types of home-based experiences: family care, in-home care, and relative care. Family care is defined as care provided for a small group of children in a private home by a nonrelative. In-home care is care provided within the child's home by a person other than a parent or relative. Relative care is care provided by a related person other than the parent, either in the child's or relative's home. The final category of experiences was called No Extra care, and indicated that the child did not have any of the above extra experiences prior to kindergarten entry.

Reliability of the ECEI was established in three ways. First, each survey was checked to ensure that it was completed correctly, and that indications of center-based experiences did not overlap with indications of No Extra care. Across all 3,969 interviews, 96\% were completed correctly. Second, the veracity of parental report information on the parameters of the services-including the duration of experiences, hours per week of attendance, on-site parentcaregiver contact, and center addresses-was cross-checked with each program's documented guidelines and parameters. These checks revealed an $85 \%$ accuracy rate. Finally, a random sample of interviews were cross-referenced with administrative records for known early childhood programs, and resulted in a concordance rate greater than $80 \%$.

Performance assessments. Standardized performance assessments were used to measure entry level readiness and student progress across kindergarten. These assessments were routine conducted by all the kindergarten teachers in the school district and were designed to inform curriculum and serve as the basis of parent-teacher conferences. Teachers rated each skill level on a 3-point Likert scale ( $1=$ Improvement Needed, $2=$ Making Progress, 3 = Competent). For this study five performance assessments were used representing distinct dimensions of early childhood achievement: three cognitive/verbal (Language Arts Skills, Mathematics Skills, Social Knowledge) and two motor/behavioral (Motor Skills and Work Habits). Correlations among performance measures range from moderately low to moderately high ( $r=.36$ to .73). Language Arts and Mathematic Skills were correlated at a moderately high level $(r=$ .73) but at a lower level with Motor Skills and Work Habits ( $r=.48-.51)$. Motor Skills and Work Habits were correlated at a moderate level ( $r=.60$ ). Social Knowledge was moderately correlated with Language Arts and Mathematics ( $r=.51)$ but correlated at a lower level with Motor Skills and Work Habits $(r=.37)$. Descriptions of the measures and their reliability and validity are presented below.

Language Arts Skills. The Language Arts Performance Assessment (LAPA) is a teacher evaluation of children's language achievement. There are 18 items rated on a 3- 
point scale ( $1=$ Improvement Needed, $2=$ Making Progress, $3=$ Competent $)$. These items included, for example, "understanding print as a form of communication," "recognizes letters," "listens and responds to literature," and "identifies similarities and differences." Performance scores across all 18 variables were averaged to create composite scores. Each composite score was then standardized using the entire cohort of kindergarten language arts performance assessments $(N=15,345)$. Internal consistency was demonstrated for the LAPA $(r=.93, p<$ $.001)$. Criterion-referenced validity for the LAPA was established with the Cognitive subscale of the Child Observation Record (COR; High/ Scope Educational Research Foundation, 1992; Schweinhart, McNair, Barnes, \& Larner, 1993; $r=.36, p<.0001)$, and the Verbal Subscale of the Differential Ability Scales (DAS; The Psychological Corporation, $1990 ; r=.51, p<.001$ ). The predictive validity of the LAPA was confirmed by examining its relationship to the second grade Reading Total score on the TerraNova (TerraNova-Second Edition; McGraw Hill, 1997) $(r=.49, p<.0001)$.

Mathematics skills. The Mathematics Performance Assessment (MPA) is similar in format to the Language Arts Performance Assessment, and consists of 17 items rated on the same 3-point scale. Items include, for example, "matches items one to one," "arranges objects according to size," "recognizes numerals," and "is aware of the concept of addition as joining sets." Performance scores across all 17 variables were averaged to create composite scores and were standardized similarly to Language Arts assessments. Internal consistency was demonstrated for the MPA $(r=.89, p<.001)$. Criterion-referenced validity for the MPA was established with the Cognitive subscale of the COR ( $r=$ $.28, p<.001)$, the Test of Early Mathematics Ability (TEMA; Ginsburg \& Baroody, 1990; $r$ $=.46, p<.05)$, and the Verbal subscale of the DAS $(r=.33, p<.001$; note significant though lower correlations than with the LAPA). The predictive validity of the MPA was confirmed by examining its relationship to the second grade Mathematics score on the TerraNova $(r$ $=.34, p<.0001$ ).
Motor skills. The Motor Skills Performance Assessment (MSPA) is a teacher evaluation of children's physical development, including fine and gross motor skills. There are 16 items rated on the same 3-point scale. Items include "runs," "hops," "skips," "holds a writing utensil properly," "cuts on a line," and "ties shoes." Performance scores across all 16 variables were averaged to create composite scores and standardized using the entire cohort of kindergarten motor performance assessments. Internal consistency was demonstrated ( $r=.89$, $p<.001$ ), and criterion-referenced validity was established with the Movement and Coordination subscale of the COR $(r=.29, p<.001)$. The MSPA was not significantly correlated with the Verbal subscale of the DAS.

Social knowledge. The Social Knowledge Performance Assessment is a teacher evaluation of student's social knowledge. Examples of the nine items, rated on the same 3point scale, include "knows full name," "knows full address," "identifies family members and their roles," and "identifies people and places in the neighborhood." Performance scores across all nine variables were averaged to create composite scores and standardized using the entire cohort of kindergarten performance assessments. Internal consistency was demonstrated $(r=.70$, $p<.001$ ), and criterion-referenced validity was established with the Social Engagement subscale of the COR $(r=.20, p<.01)$. Social Knowledge was significantly correlated with the Verbal Subscale of the DAS $(r=.41, p<.001)$.

Work habits. The Work Habits Performance Assessment (WHPA) is a teacher evaluation of children's learning behaviors during school-related tasks. There are five items rated on the same 3-point scale. Sample items include "follows directions," "completes tasks independently," and "demonstrates attention span appropriate to tasks." Performance scores across all five indicators were averaged to create composite scores and standardized using the entire cohort of kindergarten performance assessments $(\mathrm{N}=15,345)$. Internal consistency was demonstrated for the WHPA $(r=.90, p<$ $.001)$. Criterion-referenced validity for the WHPA was established with the Social Engage- 
ment subscale of the COR $(r=.26, p<.001)$, and the Learning Behaviors Scale (LBS; Stott, McDermott, Green, \& Francis, 1988) $(r=.48, p$ $<.0001)$. Work Habits was not significantly correlated with the Verbal subscale of the DAS.

Kindergarten attendance. Children's attendance was collected for three time periods across the kindergarten year. This variable represents the percentage of days that the child was present out of the total school days in a given time period.

Family poverty. Family income qualification for the Free and Reduced Lunch program was used as a family indicator of poverty. Families qualify for participation in this program if they are receiving TANF public assistance or provide documentation of lowincome status.

Maternal education. Mother's educational level at child's birth was derived from the Department of Health's Vital Statistics database. The database includes the highest level of maternal education completed in years. For the purpose of this study, mother's failure to complete high school $(<12$ years of education) was hypothesized as a risk factor for the child's poor educational outcome.

Neighborhood context. Neighborhood constructs were measured using information from the city's integrated aggregate data system for children (KIDS). KIDS contain integrated administrative databases aggregated at the block group level including Public Health, Protective Services, and Housing Property. Census block-group level data were obtained for the 1,801 block groups comprising the urban center. Data reduction techniques with 55 block-level variables were employed to define empirically "neighborhood" while accounting for colinearity among variables (McDermott, McWayne, Fantuzzo, \& Culhane, 2003). A series of exploratory common factor analyses yielded two unique and robust factors representing neighborhood context: Social Problems and Structural Danger ( $r=.81$ and .85 , respectively). Standard scores were computed across the 1,801 block groups for each dimension. Based on children's residence block-group, standard scores for each dimension were used to represent neighborhood context. Neighborhoods with a high score on the Social Problems dimension have elevated rates of truancy, child poverty, teen births, delinquent and dependent out of home placements, and substantiated abuse and neglect cases. Elevated scores on the Structural Danger dimension indicate neighborhoods with high density of dangerous properties, incidences of residence fires, and lead levels that exceed maximal allowances.

School region. Elementary schools in the large urban school district are distributed equally into nine geographic regions. These regions were used to nest schools (for data analyses) and account for any regional differences.

\section{Procedures}

A representative sample of participants was drawn from 172 public elementary schools within the large urban school district. Schools were selected to be representative of the demographic and economic distributions of each region and the district as a whole. Selected children within each school were representative of age, gender, racial, and economic distribution of the region. This study involved the collection of three types of data: (a) the Early Care and Education Interview; (b) kindergarten children's gender, ethnicity, and block-group level identification; and (c) performance assessments of children's literacy, numeracy, motor development, social knowledge, and school attendance.

Prior to the start of the school year, research team members and district officials met to draft a confidentiality agreement and data collection procedures. Subsequently, kindergarten teachers were provided with materials and instructions for the completion of parent interviews. Teachers conducted one-on-one structured interviews with parents of incoming kindergarten children in the first week of school, which is a time set aside for kindergarten teachers to spend time in their classrooms before the children arrive. Next, the enrollment database that includes children's demographic information and free and reduced lunch status was obtained and linked to the information collected from structured interviews by district data 
managers. Records from each respective database were matched according to district-assigned child identification numbers and verified with child name, teacher and school name, and child birth date. A random sample of linked records was checked for accuracy and found to be $100 \%$. Finally, teachers collected performance assessments across three points in time throughout the kindergarten year. At the end of the school year, this performance database was obtained and linked to the existing study sample database by matching child identification numbers. Block-group density of Structural Danger and Social Problems contained in the KIDS database were linked to individual child information by geocodes within the school district's database. These geocodes represented the census block group within which children resided when they registered for kindergarten at the beginning of the school year. Partnership between school district and the city's Department of Health permitted researchers to use the birth record to identify level of maternal education. Finally, all student identifiers were stripped and the de-identified, archival dataset was provided to the investigators. These procedures outlined in the confidentiality agreement were designed to protect fully the privacy of the individual student records.

\section{Data Analyses}

To determine the relationship between relevant child, family, and neighborhood variables, school regions, early care and education experiences, and kindergarten performance and attendance outcomes, multiple logistic regression was conducted. This method was used to assess the status of each independent (explanatory) variable as a risk or protective factor for later school success, while simultaneously allowing for statistical control of the independent effects of all other predictors. Multiple logistic regression created statistical models based on the combination of explanatory variables to predict classification of children into two groups based on performance outcomes: poor versus adequate. Performance outcome variables were classified dichotomously based on the sample distribution. Scores in the top $85 \%$ placed children in the "adequate" school performance group, whereas scores in the bottom $15 \%$ classified children's outcomes as "poor." This cutoff comports with the second standard deviation of proficiency and provides enough cases on both sides of the dichotomy to enable sufficient statistical power. Using multiple logistic regression, dichotomous independent and dependent variables allow for the calculation of odds ratios. This statistic is more easily interpretable as the degree of risk or protection exerted by the independent variables on each dependent variable (e.g., an odds ratio of 2 means that participating in a center-based early learning experience resulted in twice the likelihood that a child would do well in kindergarten mathematics).

One set of logistic regression analyses was run using the full sample. A series of six separate logistic regression analyses were conducted to examine the independent effects of demographics and school regions. These analyses also examined the independent effects of early care and education experiences and the interaction effects of these experiences and neighborhood context, controlling for the effects of demographic and school region variables. The overall chi-square (score statistics) was examined for each logistic regression model. Significant score statistics indicated that at least one explanatory variable was statistically significant and thus individual Wald chisquares were examined. Where significant Wald chi-squares were present, odds ratios of significant risk or protective factors were inspected visually to assess their relative importance for each outcome variable. A sample size of 3,969 provides sufficient power to detect a small effect. With 22 explanatory variables, a minimum sample of 2,136 is needed to detect a small effect (.1) with $\alpha=.05$ where power $=$ .80 (Faul \& Erdfelder, 1992).

To determine the relative significance of center-based early childhood experiences on kindergarten performance across the school year a two-way analysis of covariance was conducted. The analysis of covariance provides increased precision by statistically controlling the sources of variation not directly manipulated by the experimenter (Glass, Peckham, \& Saunders, 1972). The first factor of the ANCOVA had two levels: (a) formal, center- 
based early care and education experiences and (b) other care (informal home-based care and no extra care). The second factor was held as repeated measures corresponding to three reporting periods across the school year. Ethnicity, family poverty, and maternal education were included as covariates to control for the significant effects of these variables on child performance outcomes. A power analysis was conducted to determine the necessary sample size to detect a small effect of .1 where $\alpha=.05$ and power is set at .80 . This analysis indicated that for two groups we would need a sample of at least 788 (Faul \& Erdfelder, 1992).

A series of five repeated-measures ANCOVA were conducted representing the five outcome indicators, and significant main effects as well as interaction effects were explored using the $F$ statistic. The Bonferroni correction was used for each individual ANCOVA ( $\alpha=.01$ per dependent variable) to reduce the likelihood of making a Type I error. Where significant differences were found, Tukey's post hoc analyses were employed to determine where individual differences existed.

\section{Results}

\section{Distribution of Early Care and Education Experiences}

A series of descriptive analyses were conducted to determine the distribution of early care and education experiences for the sample. Overall, it was found that $21 \%$ of children did not participate in an early care and education experience, $64 \%$ participated in a center-based experience, and $15 \%$ participated in an informal home-based experience. Gender and ethnic differences in experiences were tested using the chi-square statistic. There were no significant gender differences in children's experiences $\left(\chi^{2}(2, N=3,969)=2.23, p=.327\right)$. There were, however, significant ethnic differences $\left(\chi^{2}(10, N=3,969)=260.09, p<.0001\right)$. White and African American children experienced greater proportions of center-based care (67\% and $69 \%$, respectively), and Hispanic and Asian children were more likely to have no extra experiences ( $41 \%$ and $56 \%$, respectively) prior to kindergarten entry.

\section{School Region, Child Demographic, Family Context, and Neighborhood Context Variables}

Multiple logistic regression tests of the effects of schools nested within school regions did not indicate a significant impact on school outcomes. Therefore, school region was not included in the final regression models. Table 1 shows the bi-univariate relationships between child demographics and family and neighborhood context variables. Although both the Structural Danger and Social Problems dimensions of neighborhood risk were significantly correlated with the outcomes, when considered simultaneously in a multiple logistic regression model with demographic and family context variables they did not contribute unique variance. The Score statistic indicated that demographic and family context variables were significantly related to children's kindergarten readiness outcomes across all regression models. Table 2 presents the odds ratios and probability levels for the independent effects of each demographic and family context factor on each performance assessment score at the beginning of kindergarten. Children's age, gender, ethnicity, family poverty, and maternal education were significantly related to Language Arts performance at the beginning of kindergarten, Score $(9, N$ $=3,328)=130.88, p<.0001)$. Younger children, boys, students of African American or Hispanic ethnic backgrounds, children who qualify for free/reduced lunch, and children whose mother did not complete 12 th grade were at greater risk for poor Language Arts outcomes in the beginning of kindergarten. For Mathematics, children's age, gender, ethnicity, family poverty, and maternal education were significant predictors, Score $(9, N=3325)=$ $116.53, p<.0001$. Similar to Language Arts, younger children, boys, African American and Hispanic children, children who qualify for free/reduced lunch, and children whose mother did not complete 12 th grade were more at risk for negative outcomes. In relation to children's motor skills, age, gender, family poverty, and maternal education were significant risk factors and being African American or Asian was a significant protective factor, Score $(9, N=$ $3,629)=135.25, p<.0001$. 


\section{Table 1}

\section{Correlations Between Child, Family, and Neighborhood Variables, and Performance Outcomes}

\begin{tabular}{lccccc}
\hline & \multicolumn{5}{c}{ Performance Assessments } \\
\hline Variables & $\begin{array}{c}\text { Language } \\
\text { Arts }\end{array}$ & Mathematics & $\begin{array}{c}\text { Social } \\
\text { Awareness }\end{array}$ & $\begin{array}{c}\text { Motor } \\
\text { Skills }\end{array}$ & $\begin{array}{c}\text { Work } \\
\text { Habits }\end{array}$ \\
\hline Child Age & $.06^{* *}$ & $.07^{* *}$ & .02 & $.06 * *$ & $.04^{*}$ \\
Family Poverty & $.15^{* *}$ & $.13^{* *}$ & $.08^{* *}$ & $.07^{* *}$ & $.08^{* *}$ \\
Maternal Education & $.21^{* *}$ & $.19^{* *}$ & $.16^{* *}$ & $.13^{* *}$ & $.11^{* *}$ \\
Neighborhood Structural Danger & $-.16^{* *}$ & $-.15^{* *}$ & $-.09^{* *}$ & $-.06^{* *}$ & $-.08^{* *}$ \\
Neighborhood Social Stress & $-.18^{* *}$ & $-.17^{* *}$ & $-.12^{* *}$ & $-.07^{* *}$ & $-.07^{* *}$ \\
\hline Note. $* * p<.0001 . * p<.01$. & & & & & \\
\hline
\end{tabular}

Similar patterns of results were found for social and behavioral readiness outcomes. Gender, ethnicity, family poverty, and maternal education were significant risk factors for poor social knowledge outcomes, where boys and children from Hispanic or Asian backgrounds, children who qualify for free/reduced lunch, and children whose mother did not complete 12th grade were at a significantly greater risk than other children, Score $(9, N=3,520)=91.33, p<$ .0001 . Significant risk factors for poor work habits were child age, gender, ethnicity, and maternal education, Score $(9, N=3,645)=99.44, p<$ .0001 . For this performance assessment, younger children, boys, Hispanic children, and children whose mother did not complete 12th grade were significantly more at risk for poor work habits. Both risk and protective factors were found for children's attendance at the beginning of kindergarten, Score $(9, N=3,688)=103.33, p<$ .0001 . Asian children were more than twice as likely to demonstrate positive attendance, whereas children living in families who qualify for free/reduced lunch or whose maternal education level is below 12th grade were significantly more likely to have poor attendance.

\section{Early Care and Education Experiences and Early School Success}

The score statistic was significant for all multiple logistic regression models evaluating the effects of early care and education experiences accounting for significant demographic and neighborhood variables. Table 2 presents the odds ratios and probability levels for the independent effects of early care and education on early school success. Early care and education experiences were significantly related to children's performance assessments in Language Arts. It was found that children who participated in center-based experiences were significantly more likely than children with no extra care to do well in Language Arts, $\mathrm{S}(11, N=3,328)=170.71$, $p<.0001$. Furthermore, children who had informal home-based experiences were significantly more likely than children with no extra care to do well in Language Arts. Similar results were found for mathematics, where children with center-based or Informal experiences were significantly more likely to do well than children with no extra care, $\mathrm{S}(11, N=3,325)$ $=160.58, p<.0001$.

For each of the social and behavioral outcomes no significant findings were discovered for children who had informal experiences. Children with center-based experiences were significantly more likely to demonstrate advanced motor skills, $\mathrm{S}(11, N=$ $3,629)=140.41, p<.0001$, social knowledge, $\mathrm{S}(11, N=3,520)=105.34, p<.0001$, and have better attendance, $\mathrm{S}(11, N=3,688)=$ $124.03, p<.0001$. Specific tests of the inter- 
Table 2

Odds Ratios and Probability Levels for Demographic, Neighborhood, and Early Care and Education Experience variables on Positive School Outcomes at the Beginning of Kindergarten

\begin{tabular}{|c|c|c|c|c|c|c|}
\hline \multirow[b]{2}{*}{$\begin{array}{l}\text { Risk/Protective } \\
\text { Factor }\end{array}$} & \multicolumn{6}{|c|}{ Outcome Variable } \\
\hline & $\begin{array}{c}\text { Language } \\
\text { Arts } \\
(N=3328)\end{array}$ & $\begin{array}{l}\text { Mathematics } \\
(N=3325)\end{array}$ & $\begin{array}{c}\text { Motor } \\
\text { Skills } \\
(N=3629)\end{array}$ & $\begin{array}{c}\text { Social } \\
\text { Awareness } \\
(N=3520)\end{array}$ & $\begin{array}{c}\text { Work } \\
\text { Habits } \\
(N=3645)\end{array}$ & $\begin{array}{l}\text { Attendance } \\
(N=3688)\end{array}$ \\
\hline Gender (boys) & $.65^{* * * *}$ & $.68 * * *$ & $.60^{* * * * *}$ & $.78 *$ & $.50 * * * *$ & .95 \\
\hline Age & $1.06 * * * *$ & $1.06 * * * * *$ & $1.08 * * * * *$ & 1.03 & $1.05 * * * *$ & 1.02 \\
\hline African American & $.66^{*}$ & $.68^{*}$ & $1.85^{* * * * *}$ & 1.02 & $.75^{*}$ & 1.15 \\
\hline Hispanic & $.50^{* * *}$ & $.50 * * *$ & 1.10 & $.55^{* * * *}$ & .71 & 1.07 \\
\hline Asian/Other & .68 & .94 & $2.99 * *$ & $.55^{*}$ & 1.45 & $2.69^{*}$ \\
\hline Family Poverty & $.75 * *$ & $.75^{* * *}$ & $.81^{*}$ & $.74 * *$ & .88 & $.52 * * * *$ \\
\hline Maternal Education & $.61^{* * * * *}$ & $.60 * * * *$ & $.68^{* * * *}$ & $.70^{* * * *}$ & $.64 * * * *$ & $.58 * * * *$ \\
\hline Structural Danger & .79 & .89 & .88 & .89 & .88 & 1.09 \\
\hline Social Stress & .92 & .92 & .84 & .99 & 1.14 & .80 \\
\hline Center-based Care & $2.02 * * * *$ & $2.16 * * * *$ & $1.61 * * * *$ & $1.43^{* *}$ & 1.18 & $1.56^{* * * * *}$ \\
\hline Informal Care & $1.62 * *$ & $1.78 * *$ & 1.38 & 1.13 & 1.30 & 1.30 \\
\hline
\end{tabular}

$* p<.05 . * * p<.01 . * * * p<.001 . * * * * p<.0001$.

Note. Significance is based on Wald chi-square statistics. An odds ratio less than 1 indicates a risk factor for positive school outcomes, whereas an odds ratio greater than 1 indicates a protective factor.

actions between center-based early care and education experiences and neighborhood context revealed no significant interactions.

\section{Effects of Early Care and Education Experiences Across Time}

Two-way ANCOVAs were conducted to analyze the effects of center-based early care and education across time, controlling for significant child and family variables. Standardized performance assessments were applied as the repeated measure to evaluate Language Arts, Mathematics, Motor Skills, Social Knowledge, and Work Habits outcomes across the kindergarten year. Table 3 presents mean scores and significant group differences for each standardized performance assessment across time.

For Language Arts, significant main effects were found for early care and education experiences, $F(1,3146)=71.45, p \leq .0001$ and time, $F(2,3145)=2264.73, p \leq .0001$. Across all three points in time, children with centerbased experiences scored significantly greater than children without these experiences (effect size $=.31, .29$, and .25 , respectively). Furthermore, Language Arts scores at the end of the year (Time 3 ) were significantly greater than scores in the middle of the year (Time 2), and midyear scores were significantly greater than beginning of the year scores (Time 1). An 
Table 3

Mean Kindergarten Performance Assessments: Center-Based Care and Education Across Time

\begin{tabular}{lccc}
\hline & \multicolumn{3}{c}{ Standard Scores } \\
\cline { 2 - 4 } Performance Area & Time 1 & Time 2 & Time 3 \\
\hline
\end{tabular}

Language Arts $(N=3,151)$

Center-based care

Other care

Mathematics $(N=3,180)$

Center-based care

Other care

Motor Skills $(N=3,418)$

Center-based care

Other care

Social Knowledge $(N=3,294)$

Center-based care

Other care

Work Habits $(N=3,465)$

Center-based care

Other care
$49.88(9.52)$

$46.88(10.13)$

$55.03(9.13)$

$52.26(10.06)$

$58.99(8.72)$

$56.63(10.23)$

$56.12(7.42)$

$54.47(8.80)$

$47.24(10.55) \quad 51.04(9.05)$

$55.73(8.10)$

$58.93(6.57)$

$54.10(8.88)$

$57.69(7.58)$

$47.43(9.96)$

$49.88(9.19)$

$54.00(7.48)$

$56.66(6.42)$

$47.47(9.92)$

$52.15(8.50)$

$54.76(7.72)$

\begin{tabular}{llll} 
& $49.05(9.16)$ & $51.67(8.40)$ & $53.28(7.90)$ \\
Other care & $48.64(9.34)$ & $51.33(9.02)$ & $52.80(8.51)$ \\
\hline
\end{tabular}

Note. Numbers in parentheses represent standard deviations.

identical pattern of results was found for Mathematics. Significant main effects were found for early care and education experience, $F(1$, $3175)=45.51, p \leq .0001($ effect size $=.25$, .20 , and .20 , respectively), and time, $F(2,3174)$ $=1276.57, p \leq .0001$.

Likewise, the ANCOVAs for Social Knowledge and Motor Skills showed the superiority of center-based care and the positive effect of kindergarten experience. Significant main effects for children's motor skills were found for type of early care and education experience, $F(1,3413)=34.51, p \leq .0001$. Across all three points in time, children with centerbased experiences scored significantly greater on Motor Skills than children without centerbased experiences (effect size $=.19, .19$, and .18 , respectively). Significant main effects were also found for time, $F(2,3,412)=2448.07, p \leq .0001$. For Social Knowledge, significant main effects were found for type of early care and education, $F(1,3,289)=65.09, p \leq .0001$ and time, $F(2$, $3,288)=1236.83, p \leq .0001$. Across all three points in time, children with center-based experiences scored significantly greater on social knowledge than children without center- 
based experiences (effect size $=.25, .23$, and .27 , respectively). Additionally, performance was significantly greater at Time 3 than at Time 2 , and Time 2 motor skills were significantly greater than skills at Time 1.

Children's work habits significantly increased across kindergarten, $F(2,3,459)=$ $607.27, p \leq .0001$; however, there was no significant main effect for care and education experience. Work habits scores at the end of the year (Time 3 ) were significantly greater than scores in the middle of the year (Time 2), and mid-year scores were significantly greater than beginning of the year scores (Time 1).

\section{Discussion}

The primary objective of this research was to conduct a population-based investigation of the unique protective influence of center-based early care and education experiences on kindergarten outcomes. To fulfill this objective, it was important to understand how school region, neighborhood context, family context, and child demographic variables related to academic and behavioral outcomes at kindergarten entry. The unique influence of children's center-based experiences upon kindergarten entry and across kindergarten was then explored by controlling for these variables.

\section{Demographic and Context Variables}

The first assessment, early in the kindergarten year, revealed overall that younger kindergarten children and boys were more likely to evidence lower levels of academic and behavioral competencies than older children and girls. This supports previous literature documenting systematic age and gender differences in young children's cognitive and behavioral school outcomes (Holahan et al., 2002; Kurdek \& Sinclair, 2001; NICHD Early Child Care Research Network, 2002). With respect to racial/ethnic minority differences, African American, Hispanic, and Asian children were more likely to show lower levels of language arts early in the kindergarten year than Caucasian children. African American and Hispanic children also demonstrated early risks in mathematics and work habits skills as compared to
Caucasian children. These findings comport with recent national studies of kindergarten performance showing lower school outcomes for African American and Hispanic children compared to Caucasian (West, Denton, \& Germino Hausken, 2000). In addition to demonstrating lower levels of language arts skills, Asian and Hispanic children evidenced lower levels of social knowledge. Because this dimension captures children's ability to verbalize personal knowledge of their social environment (e.g., knowledge of home address, role of family members), it is likely that children whose native language is not English would have increased difficulty. In the present study, African American children showed a significantly higher level of motor skill development than the Caucasian children early in the kindergarten year. West and his colleagues (2000) also found similar results. Asian children demonstrated high levels of attendance. This finding is consistent with literature that highlights the cultural value of school participation for Asian families (Steinberg, 1996).

Findings from this study support the hypothesis that specific factors within the family context significantly account for unique variance in children's early school success. Both family poverty and low maternal education (less than high school diploma) were significant risk factors for poor academic and behavioral outcomes controlling for child demographics and neighborhood risk factors. These data support the general research underscoring the proximal influence of the family context and the specific research on the impact of poverty and maternal education and early school success (Axinn et al., 1997; Christian et al., 1998; Duncan et al., 1994).

Empirically derived dimensions of neighborhood risk were significantly correlated with outcomes. However, they did not account for a unique amount of variance in academic and social outcomes in our multivariate models. Family poverty and maternal education were dominant in the model and showed unique relationship with outcomes. Significant relationships between these family and neighborhood risk factors (significant correlations ranged from .20-.41) indicated that family 
poverty and low levels of maternal education were highly associated with living in neighborhoods with the highest density of structural danger and social problems.

Although the neighborhood dimensions did not account for unique variance in our multivariate model, the current study extends the neighborhood risk literature by applying latent structures of neighborhood risk factors, derived from an entire urban population, to understand the influence of neighborhood risk on kindergarten performance. This inquiry enabled researchers to examine relationships between a broad range of contextual risk factors evident across an entire population. Furthermore, whereas previous literature has examined specific individual neighborhood risk variables that have known relationships with one another (e.g., poverty and crime), the latent dimensions utilized in this study accounted for colinearity among an array of 55 blocklevel neighborhood risk variables tracked routinely by municipal governments. These techniques allowed researchers to account for distinct dimensions of neighborhood risk associated with living in a large urban center and to examine how these dimensions relate to individual child outcomes in a complex multivariate model include child and family context variables.

\section{Early Care and Education Experiences}

For the children entering kindergarten in a large, urban public school district, nearly twothirds had formal, center-based child care experience prior to kindergarten (64\%). Approximately one of five had no extra child care experiences $(21 \%)$ and $15 \%$ had informal, homebased experiences. These prevalence figures are supported by the Early Childhood Longitudinal Study of kindergarten children conducted by National Center for Educational Statistics. The kindergarten data, involving a nationally representative sample of kindergarten children, showed that $69 \%$ of the children entering kindergarten had a formal, centerbased experience prior to kindergarten (West et al., 2000). In the present study, Hispanic and Asian families evidenced a different pattern of child care use than Caucasian and African
American families. The Hispanic and Asian families tended to be less likely to utilize center-based child care and more likely to keep their children at home. In the urban setting where this research was conducted, the findings may reflect the limited language capacity of center-based programs for Hispanic and Asian families and issues related to recent immigration to the urban setting.

Controlling for demographic, family, and neighborhood risk factors, this study demonstrated that children who participated in formal, center-based early childhood programs prior to public school entry performed at higher levels than their peers across all academic and social areas in kindergarten. At kindergarten entry, children with center-based experiences performed significantly better than their peers with other care experiences (informal experiences or no extra child care experiences) in language arts, mathematics, motor skills, social knowledge, and attendance. In addition to advantages at the beginning of the year, children who participated in center-based early learning experiences retained their advantage throughout the kindergarten year. At the end of kindergarten, children with center-based early learning experiences evidenced significantly greater literacy, mathematics, motor skills, and social knowledge outcomes than their peers who had other care experiences.

These findings support existing literature that has documented the impact of center-based early childhood programs on children's academic outcomes. Model early intervention programs, such as High/Scope Perry Preschool Project and the Carolina Abcedarian Project, have demonstrated significant improvement on children's early reading and mathematics achievement while in preschool (Campbell \& Ramey, 1994; Schweinhart \& Weikart, 1997). Others have documented increases in general knowledge, verbal intelligence, vocabulary, and mathematics (Burchinal, Ramey, Reid, \& Jaccard, 1995; Christian et al., 1998).

This research also supports previous findings that have established relationships between children's early experiences and later social and behavioral functioning. Studies have documented an increase in positive class- 
room behavior, social engagement, and cooperation with peers for children who participate in center-based early childhood programs (Burchinal et al., 1995; Christian et al., 1998; Clarke-Stewart, 1991; Creps \& Vernon-Feagans, 1999). Similarly, children who participate in center-based experiences have demonstrated greater complexity and social competence during play with peers (Aureli \& Colecchia, 1996).

Similar to preschool findings, longitudinal research has emphasized the long-term benefit of center-based child care experiences on children's later academic and social success (Broberg, Wessels, Lamb, \& Hwang, 1997; Burchinal, Campbell, Bryant, Wasik, \& Ramey, 1997). Barnett (1995) provided a review of longitudinal research examining the effects of model demonstration projects and large-scale public programs designed for children from economically disadvantaged families. He found that participation in such programs can produce sizable effects on later school achievement, grade retention, placement in special education, and social adjustment up to 15 years after program participation. Longitudinal follow-up of children who participated in the Abcedarian program demonstrated increased reading and mathematics achievement that extended through age 21 (Campbell et al., 2001). Other research has documented that early experience in child care predicted gains in social competence immediately following program participation that remained relatively stable from preschool through age 15 (Campbell, Lamb, \& Hwang, 2000).

Whereas immediate and long-term effects have been established for a variety of specific intervention programs such as those cited above (e.g. Campbell \& Ramey, 1994; Schweinhart \& Weikart, 1997), much less is known about the positive benefits across a variety of early experiences and for populations of children experiencing a full range of risk factors. In fact, Barnett (1995) reports that among the studies in his review, only the Abcedarian project explored the effects of participation in a variety of child care experiences. Researchers found that compari- son group children who participated in community-based programs that met federal guidelines for quality had higher IQ scores than children who did not, though the effect size was half that of the Abcedarian program (Burchinal, Lee, \& Ramey, 1989).

Since Barnett's review (1995), some recent national studies have highlighted the value of formal, center-based experiences and therefore, lend support to the findings of the present study. Findings from the Early Childhood Longitudinal study have indicated that children who had experienced center-based care prior to kindergarten were more likely to score higher on reading and mathematics assessments than children who did not have these experiences (Innes, Denton, \& West, 2001). The NICHD Study of Early Child Care has evaluated the effects of a range of child-care experiences. This study examined parent's natural selection of child care experiences and was therefore able to examine individual outcomes for children across a variety of early experiences. Thus far, findings from this study have reported child outcomes up to 4.5 years of age. Overall, researchers have found that children who participate in center-based early learning experiences demonstrate significantly better cognitive and language skills by kindergarten entry as compared to children without these experiences (NICHD Early Child Care Research Network, 2002). Positive relations have also been found between experience in formal child care and children's social and behavioral outcomes (Belsky, 2002; NICHD Early Child Care Research Network, 2001b).

Although this NICHD Study was designed to study the effects of center-based experiences for all children including those amidst multiple risk factors, it did not intentionally target children at highest risk in most dense urban settings. For example, children living in dangerous neighborhoods in large complex urban settings and those born to a teen mother were excluded from the NICHD study (NICHD Early Child Care Research Network, 1994). Therefore, the findings are not necessarily representative of all children living in our largest urban centers-particularly for children living in the most disadvantaged urban neighborhoods. 


\section{Implications for Future Research and Practice}

The current short-term longitudinal, population-based study of center-based child care and education makes a contribution to the research literature by accounting for the range of relevant family and neighborhood risk factors while examining the unique relationship between center-based experiences and kindergarten competency outcomes. This study highlights the protective benefit of center-based experiences for a variety of child outcomes. The objectives of this research were not to evaluate the effects of specific early childhood programs, but rather to account for children's participation across the range of early centerbased care experiences including federal programs such as Head Start, private center-based care, and subsidized child care. Furthermore, this study examined the effects of these experiences on a broad range of outcomes including motor skills, work habits, social skills, and attendance.

The present study provides a macro, population-based assessment of the relationships between demographics, family context, neighborhood context, early childhood experiences and kindergarten outcomes in a large urban setting. To accomplish this investigation, researchers partnered with city and school district personnel to capitalize on well-established administrative databases. This process enabled large-scale research to be conducted within an entire municipal system serving young children. However, these databases were limited in the amount of demographic information they contained. Future research should incorporate additional parent and family variables hypothesized to influence early school success, such as parent practices, family literary, and parental involvement.

The current study was designed to include a range of center-based early childhood experiences, detailed information about specific aspects of the quality of early childhood programs was not assessed. Future inquiry should explore the hypothesized contributions of individual programmatic features such as the quality of the learning environment, staff credentials and training, and curricular foci. Future research efforts could benefit from employing additional standardized academic achievement and behavioral measures to test more specific skill sets. Multidimensional assessments of early literacy and socioemotional development, for example, could provide refined information about relationships between early experiences and early school outcomes. In the present study, academic and behavioral outcome evaluations were based on teacher assessments. In future studies, obtaining information across multiple informants, such as the parent and outside evaluators, would provide more comprehensive assessments of children's academic and behavioral functioning.

The recent No Child Left Behind legislation (U. S. Department of Education, 2002) compels early childhood educators and policy makers to focus more attention on young children's transition to elementary school. Evidence is needed to document successful programs and processes that foster productive transitions for the most vulnerable students. Given the keen interest in the impact of Head Start (U.S. Department of Health and Human Services, Administration for Children and Families, 2005), future studies can examine the specific effectiveness of Head Start upon entry to kindergarten and across primary grades within an entire municipal cohort. These quasiexperimental data will add to our understanding of Head Start contribution to school readiness for children living in poverty.

The current research contributes to this effort. It highlights the strategic importance of public school kindergarten in one large urban center by relating the unique impact of early childhood experiences on specific academic and behavioral competencies for children entering school. Furthermore, it underscores the independent impact of relevant child and family risks on school readiness competencies. Findings from this study reinforce the importance of center-based early childhood experiences to early elementary school success (National Research Council and Institute of Medicine, 2000). Unfortunately, young children from high-risk neighborhoods are less likely to have such experiences (Barnett, 1995). At this time, the challenge is twofold. First, this type of population-based research must be used 
to foster community-wide discussions aimed at connecting children living in high risk neighborhood to center-based early childhood experiences. Second, educators, researchers, and families must go beyond the mere recognition of the importance of formal preschool experience for vulnerable children. Dynamic twoway communications must be generated between formal early childhood programs and the kindergarten programs in the public school systems that receive these children (Pianta, KraftSayre, Rimm-Kaufman, Gercke, \& Higgins, 2001). Bidirectional relationships provide an opportunity for these early childhood and kindergarten programs to share resources and information. This type of collaboration has great promise to improve the quality and continuity of early learning experiences for children and their subsequent success in school.

\section{Footnotes}

${ }^{1} 110$ Hispanic and 1 Asian student in this sample were receiving services for English Language Learners.

\section{References}

Aureli, T., \& Colecchia, N. (1996). Day care experience and free play behavior in preschool children. Journal of Applied Developmental Psychology, 17, 1-17.

Axinn, W., Duncan, G. J., \& Thornton, A. (1997). The effects of parents' income, wealth, and attitudes on children's completed schooling and self-esteem. In G. J. Duncan \& J. Brooks-Gunn (Eds.), Consequences of growing up poor (pp. 518-540). New York: Russell Sage Foundation.

Barnett, W. S. (1995). Long-term effects of early childhood programs on cognitive and school outcomes. The Future of Children, 5, 25-50.

Belsky, J. (2002). Quantity counts: Amount of child care and children's socioemotional development. Journal of Developmental \& Behavioral Pediatrics, 23, 167 170.

Berry, M. (1992). Contributors to adjustment problems of adoptees: A review of the longitudinal research. Child and Adolescent Social Work Journal, 9, 525-540.

Broberg, A. G., Wessels, H., Lamb, M. E., \& Hwang, C. P. (1997). Effects of day care on the development of cognitive abilities in 8-year-olds: A longitudinal study. Developmental Psychology, 33, 62-69.

Brooks-Gunn, J., \& Chase-Lansdale, P. L. (1995). Adolescent parents. In M. Bornstein (Ed.), Handbook of parenting (pp. 113-149). Hillsdale, NJ: Erlbaum.

Burchinal, M. R., Campbell, F. A., Bryant, D. M., Wasik, B. H., \& Ramey, C. T. (1997). Early intervention and mediating processes in cognitive performance of chil- dren of low-income African American families. Child Development, 68, 935-954.

Burchinal, M., Lee, M., \& Ramey, C. (1989). Type of daycare and intellectual development in disadvantaged children. Child Development, 60, 128-137.

Burchinal, M. R., Ramey, S. L., Reid, M. K., \& Jaccard, J. (1995). Early child care experiences and their association with family and child characteristics during middle childhood. Early Childhood Research Quarterly, 10, 33-61.

Campbell, J. J., Lamb, M. E., \& Hwang, C. P. (2000). Early child-care experiences and children's social competence between 1.5 and 15 years of age. Applied Developmental Science, 4, 166-175.

Campbell, F. A., Pungello, E. P., Miller-Johnson, S., Burchinal, M., \& Ramey, C. T. (2001). The development of cognitive and academic abilities: Growth curves from an early childhood educational experiment. Developmental Psychology, 37, 231-242.

Campbell, F. A., \& Ramey, C. T. (1994). Effects of early intervention on intellectual and academic achievement: A follow-up study of children from low-income families. Child Development, 65, 684-698.

Christian, K., Morrison, F. J., \& Bryant, F. B. (1998). Predicting kindergarten academic skills: Interactions among child care, maternal education, and family literacy environments. Early Childhood Research Quarterly, 13, 501-521.

Clarke-Stewart, A. (1991). A home is not a school: The effects of child care on children's development. Journal of Social Issues, 47, 105-123.

Coulton, C., Korbin, J., \& Su, M. (1996).Measuring neighborhood context for young children in an urban area. American Journal of Community Psychology, 24, 532.

Coulton, C., Korbin, J., Su, M., \& Chow, J. (1995). Community level factors and child maltreatment rates. Child Development, 66, 1262-1276.

Coulton, C. J., \& Pandey, S. (1992). Geographic concentrations of poverty and risk to children in urban neighborhoods. American Behavioral Scientist, 35, 238-257.

Creps, C. L., \& Vernon-Feagans, L. (1999). Preschoolers' social behavior in day care links with entering day care in the first year. Journal of Applied Developmental Psychology, 20, 461-479.

Duncan, G. J., Brooks-Gunn, J., \& Klebanov, P. K. (1994). Economic deprivation and early childhood development. Child Development, 65, 296-318.

Egeland, B., Carlson, E., \& Sroufe, L. A. (1993). Resilience as process. Development and Psychopathology, $5,517-528$.

Fantuzzo, J., \& Cohen, H. L. (2003, April). The Early Childhood Experiences Survey: Building capacity to explore the link between pre-school and kindergarten experiences. In C. McWayne (Chair), Assessment and accountability in early childhood education: Building capacity through partnership in a large, urban school district. Symposium conducted at the Annual Meeting of the American Educational Research Association, Chicago, IL.

Farver, J., Natera, L., \& Froscsh, D. (1999). Effects of community violence on inner-city preschoolers and 
their families. Journal of Applied Developmental Psychology, 20, 143-158.

Faul, F., \& Erdfelder, F. (1992). GPOWER: A priori, postcompromise power analyses for MS-DOS. Born, Germany: Born University, Department of Psychology.

Ginsburg, H. P., \& Baroody, A. J. (1990). Test of Early Mathematics Ability (2 ${ }^{\text {nd }}$ ed.). Austin, TX: PRO-ED.

Glass, G. V., Peckham, P. D., \& Saunders, J. R. (1972). Consequences of failure to meet assumptions underlying the fixed effects analyses of variance and covariance. Review of Educational Research, 42, 237-288.

High/Scope Educational Research Foundation. (1992). Child Observation Record (COR). Ypsilanti, MI: High/ Scope Press.

Holahan, J. M., Shaywitz, B. A., Chhabra, V., Shneider, A., Marchione, K., Shaywitz, S. E., \& Fletcher, J. M. (2002). Developmental trends in teacher perceptions of student cognitive and behavioral status as measured by the Multigrade Inventory for Teachers: Evidence from a longitudinal study. In D. L. Molfese \& V. J. Molfese (Eds.), Developmental variations in learning: Applications to social executive function, language, and reading skills (pp. 23-52). Mahwah, NJ: Lawrence Erlbaum Associates.

Hubbs-Tait, L., Culp, A. M., Huey, E., Culp, R., Starost, H., \& Hare, C. (2002). Relation of Head Start attendance to children's cognitive and social outcomes: Moderation by family risk. Early Childhood Research Quarterly, 17, 539-558.

Innes, F. K., Denton, K. L., \& West, J. (2001, April). Child care factors and kindergarten outcomes: Findings from a national study of children. Presentation at the Society for Research in Child Development, Minneapolis, MN.

Klebanov, P. K., Brooks-Gunn, J., \& McCormick, M. C. (1994). School achievement and failure in very low birth weight children. Developmental and Behavioral Pediatrics, 15, 248-256.

Kurdek, L. A., \& Sinclair, R. J. (2001). Predicting reading and mathematics achievement in fourth-grade children from kindergarten readiness scores. Journal of Educational Psychology, 93, 451-455.

Leventhal, T., \& Brooks-Gunn, J. (2000). The neighborhoods they live in: The effects of neighborhood residence on child and adolescent outcomes. Psychological Bulletin, 126, 309-337.

Leventhal, T, \& Brooks-Gunn, J. (2003).Children and youth in neighborhood contexts. Current Directions in Psychological Science, 12, 273.

Luthar, S. S., Cicchetti, D., \& Becker, B. (2000). The construct of resilience: A critical evaluation and guidelines for future work. Child Development, 71, 543-562.

McDermott, P. A., McWayne, C. M., Fantuzzo, J. W., \& Culhane, D. (2003, March). Defining neighborhood context empirically. Paper presented at the Eastern Psychological Association's 74th Annual Meeting, Baltimore, MD.

McGraw-Hill. (1997). TerraNova, The Second Editon: California Achievement Tests. Monterey, CA: CTB/ McGraw-Hill LLC.

National Association for the Education of Young Children. (1998). Accreditation criteria and procedures of the National Association for the Education of Young Chil- dren. Retrieved August 2003 from NAEYC website: www.naeyc.org

National Center for Children in Poverty. (2002). Early childhood poverty: A statistical profile. New York: National Center for Children in Poverty, Columbia University Mailman School of Public Health.

National Research Council. (2001). Eager to learn: Educating our preschoolers. Washington, DC: National Academy Press.

National Research Council and Institute of Medicine, Board on Children, Youth, and Families, Commission on Behavioral and Social Sciences and Education. (2002). In J. P. Shonkoff \& D. Phillips (Eds.), From neurons to neighborhoods: The science of early childhood development. Washington, DC: National Academy Press.

NICHD Early Child Care Research Network. (1994). Child care and child development: The NICHD Study of Early Child Care. In S. L. Friedman \& H. C. Haywood (Eds.), Developmental follow-up: Concepts, domains, and methods (pp. 377-396). New York: Academic Press.

NICHD Early Child Care Research Network. (2000). The relation of child care to cognitive and language development. Child Development, 71, 960-980.

NICHD Early Child Care Research Network. (2001a). Nonmaternal care and family factors in early development: An overview of the NICHD Study of Early Child Care. Applied Developmental Psychology, 22, 457-492.

NICHD Early Child Care Research Network. (2001b). Child care and children's peer interaction at 24 and 36 months: The NICHD Study of Early Child Care. Child Development, 72, 1478-1500.

NICHD Early Child Care Research Network. (2002). Early child care and children's development prior to school entry: Results from the NICHD Study of Early Child Care. American Educational Research Journal, 39, 133-164.

Peisner-Feinberg, E. S., Burchinal, M. R., Clifford, R. M., Culkin, M. L., Howes, C., Kagan, S. L., et al. (2001). The relation of preschool child-care quality to children's cognitive and social developmental trajectories through second grade. Child Development, 72 , 1534-1553.

Pianta, R. C., Kraft-Sayre, M., Rimm-Kaufman, S., Gercke, N., \& Higgins, T. (2001). Collaboration in building partnerships between families and schools: The National Center for Early Development and Learning's Kindergarten Transition Intervention. Early Childhood Research Quarterly, 16, 117-132.

The Psychological Corporation. (1990). Differential Ability Scales. San Antonio, TX: Harcourt Brace \& Company,

Schweinhart, L., McNair, S., Barnes, H., \& Larner, M. (1993). Observing young children in action to assess their development: The High/Scope Child Observation Record study. Educational and Psychological Measurement, 53, 445-455.

Schweinhart, L. J., \& Weikart, D. P. (1997). The High/ Scope Preschool Curriculum Comparison study through age 23. Early Childhood Research Quarterly, 12, 117-143. 
Snow, C. E., Burns, S., \& Griffin, P. (Eds.). (1998). Preventing reading difficulties in young children. Washington, DC: National Academy Press.

Steinberg, L. (1996). Beyond the classroom: Why school reform has failed and what parents need to do. New York: Simon \& Schuster Inc.

Stott, D. H., McDermott, P. A., Green, L. F., \& Francis, J. M. (1988). Learning Behaviors Scale and Study of Children's Learning Behaviors research edition manual. San Antonio: The Psychological Corporation.

U.S. Department of Education. (1996). Urban schools: The challenge of location and poverty. Washington, DC: Author.

U.S. Department of Education. (2002). No Child Left Behind Act. Washington, DC: Author.
U.S. Department of Health and Human Services, Administration for Children and Families. (2005, May). Head Start impact study: First year findings, Washington, DC.

Weiss, A., \& Fantuzzo, J. W. (2001). Multivariate impact of health and caretaking risk factors on the school adjustment of first graders. Journal of Community Psychology, 29, 141-160.

West, J., Denton, K., \& Germino Hausken, E., (2000). American's kindergarteners (NCES 2000-070). U.S. Department of Education, NCES. Washington, DC: U.S. Government Printing Office.

Wilson, R. (1987).Risk and resilience in early mental development. In S. Chess \& A. Thomas (Eds.), Annual Progress in Child Psychiatry and Child Development (pp. 69-85). Philadelphia: Brunner/Mazel, Inc.

John Fantuzzo, PhD, is the Diana Riklis Professor of Psychology in Education, in the Policy Research, Evaluation and Measurement Program at the University of Pennsylvania. He is also the Director of Penn CHILD Research (Children's Institute of Learning and Developmental Research). Fantuzzo specializes in the population-based study of risk and protective factors that impact school readiness and early school success for low-income urban children.

Heather Rouse, MSEd, is an advanced doctoral student in the School, Community, and Clinical Child Psychology program at the Graduate School of Education, University of Pennsylvania. She is an ACF/Head Start Research Scholar, and her research interests include children's socio-emotional development and approaches to learning, kindergarten transition, school readiness, and early childhood public policy.

Paul A. McDermott, PhD, is a Professor in Policy Research, Evaluation, and Measurement at the Graduate School of Education and Professor of Psychology in Psychiatry in the School of Medicine at the University of Pennsylvania. He is a psychometrician and quantitative psychologist. His research interests include psychometrics, test development and scaling, early school emotional and behavioral adjustment, and children's approaches to learning.

Yumiko Sekino, MA, is an advanced doctoral student in the School, Community, and Clinical Child Psychology program at the Graduate School of Education, University of Pennsylvania. She is an ACF/Head Start Research Scholar, and her research interests include early childhood integrative curriculum and assessment, children's peer play skills, and parent involvement in education.

Andrea Weiss, PhD, received her doctorate from University of Pennsylvania in School, Community, and Clinical Child Psychology. She is current serving as a consultant for the Office of Early Childhood in the School District of Philadelphia. Her current research interests are early childhood education and child development.

Stephanie Childs, $\mathrm{PhD}$, received her doctorate from the University of Pennsylvania in higher education. She is the former director of kindergarten for the Philadelphia Public School District, and current Educational Director of the District's Head Start program. 